\title{
A Rare Case of Cerebral Cortical Dysplasia with Arterial Vascular Dysplasia
}

\author{
Jai Jai Shiva Shankar, Susitna Trina Banerjee, Matthew Hogan, Karel terBrugge, \\ Pierre Lasjaunias, Marlise P. dos Santos
}

\begin{abstract}
Background: Cortical dysplasias are rarely associated with vascular anomalies. They are usually associated with venous anomalies or in few cases with both arterial and venous anomalies. Methods: Twenty-six year old female presented with history of headache showed cortical dysplasia associated with pure arterial dysplasia in the absence of any associated venous anomaly. Conclusions: An abnormal arterial supply to or an abnormal venous drainage from the growing cortex may result in cortical rearrangements that eventually give rise to various neuronal migration anomalies.
\end{abstract}

RÉSUMÉ: Un cas rare de dysplasie corticale cérébrale avec dysplasie vasculaire artérielle. Contexte : Les dysplasies corticales sont rarement associées à des anomalies vasculaires. Elles sont habituellement associées à des anomalies veineuses ou à des anomalies artérielles et veineuses dans un petit nombre de cas. Méthodes : Une femme âgée de 26 ans, qui a consulté pour de la céphalée, était porteuse d'une dysplasie corticale associée à une dysplasie artérielle pure en l'absence d'anomalies veineuses. Conclusions : Un apport artériel anormal ou un drainage veineux anormal provenant du cortex en croissance peuvent provoquer des réarrangements corticaux donnant lieu éventuellement à différentes anomalies de migration neuronale.

Can. J. Neurol. Sci. 2009; 36: 757-760

Vascular anomalies along with disorders of neuronal migration are rare ${ }^{1}$. Most of these are associated with venous anomalies of the brain ${ }^{2}$. Both arterial and venous anomalies together have also been reported ${ }^{3}$. A disorder of neuronal migration associated with pure arterial dysplasia has not been reported so far in the literature. Here we describe the clinical and neuroimaging abnormalities in a patient with multifocal subependymal heterotopia and pure arterial dysplasia.

\section{CASE REPORT}

A healthy 26-year-old female participated in one of our voluntary fMRI studies. She was normal on physical and neurological examination conducted before the fMRI.

On MRI, a multifocal subependymal heterotopia was identified involving the trigone, the occipital horn and the body of the right lateral ventricle (Figure 1). The right lateral ventricle was asymmetrically dilated. There were multiple small flow voids overlying the medial aspect of the occipital lobe (Figure 1) which raised a possibility of arterio-venous malformation (AVM). However, there was no evidence of an AVM on the timeof-flight magnetic resonance angiography (TOF MRA) (Figure 2-d). Considering the limitations of TOF MRA, a conventional cerebral angiogram was performed to rule out a vascular malformation. It revealed a tangle of small, thin and tortuous P4branches of the right posterior cerebral artery in the region of the grey matter heterotopia seen on the MRI (Figure 2-a,b,c). There was no evidence of a feeding artery, early draining vein or any venous anomaly. In the absence of a vascular malformation or arteriovenous shunt these findings were considered as suggestive of an arterial dysplasia.

On further interrogation, she revealed a history of recurrent severe daily headache until the age of 13 , after which her headaches became mild with a frequency of once a month. The headache was classified as a migraine without aura. She had been taking oral contraceptive pills for a few years. Physical and neurological examinations- including visual field test conducted

From the Ottawa Hospital (JJSS, MH, MPdS), University of Ottawa (STB, MPdS), Ottawa; Division of Neuroradiology, University of Toronto (KtB), Toronto, Ontario; Diagnostic and Therapeutic Neuroradiology (PL), Centre Hospitalier, Universitaire de Bicetre, Paris, France.

Received June 11, 2008. Final Revisions Submitted June 3, 2009.

Correspondence to: Marlise P. dos Santos, University of Ottawa, The Ottawa Hospital, C151 - 1053 Carling Avenue, Ottawa, Ontario, K1Y 4E9, Canada. 


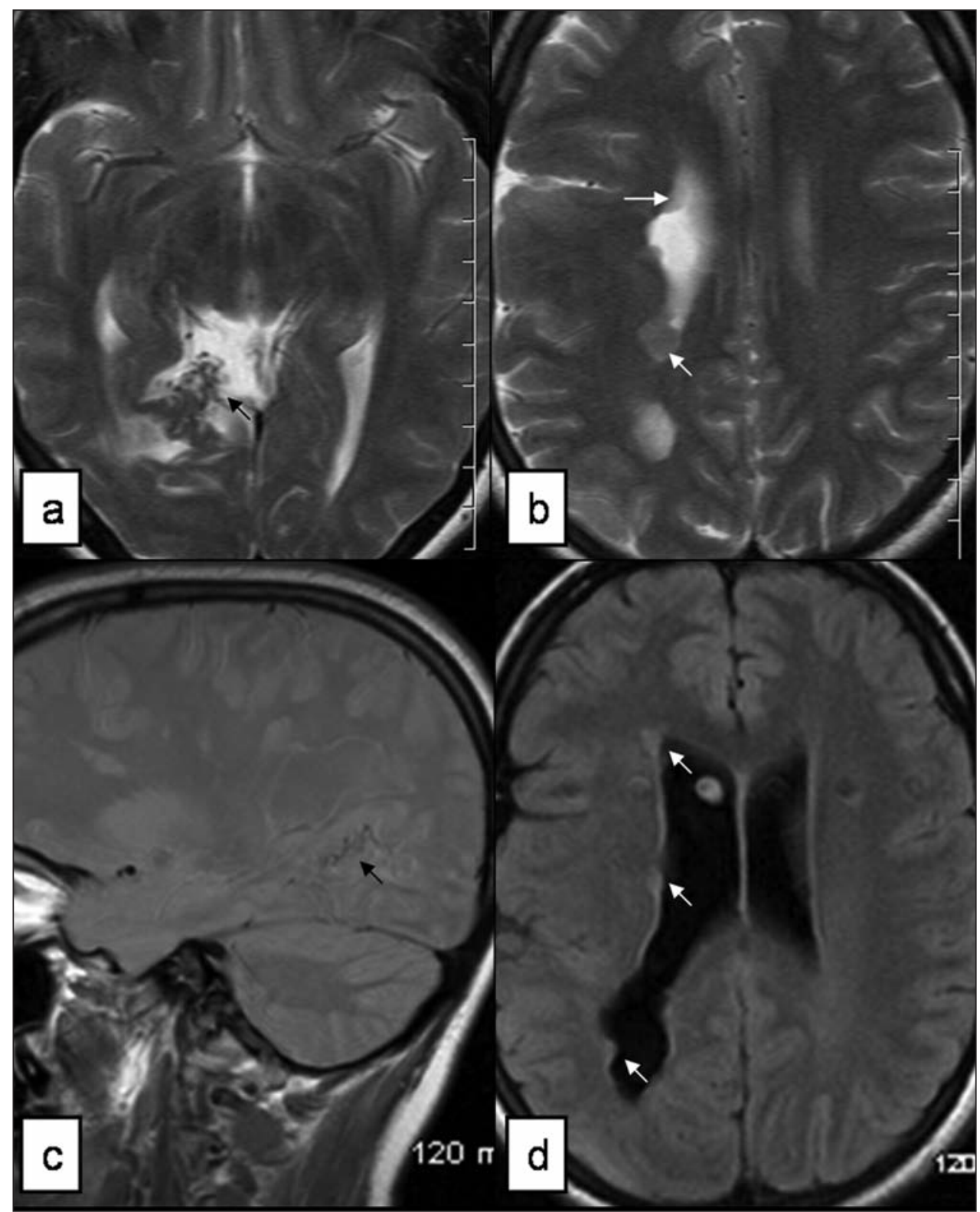

Figure 1: MRI head. (a) T2-weighted axial images showing a tangle of vessels over the medial aspect of the right occipital lobe with cortical malformation (black arrow). (b) T2-weighted axial images showing subependymal heterotopia (white arrow). (c) Sagittal PD-weighted showing flow-voids (black arrow) and (d) Axial FLAIR images showing the subependymal heterotopia (white arrow).

afterwards were normal. Symptomatic treatment for headache was recommended. Treatment of the imaging findings was not considered. The patient was kept on clinical routine follow-up with a neurologist.

\section{DISCUSSION}

During the second month of gestation, neurons start migrating from the germinal matrix radially and tangentially to their final destination in the cortex. Neurons utilize the glial radial fibers and the space that surrounds the venules for migration. The major neuronal migration takes place between 8 and 16 weeks.
Smaller waves of migration continue up to 25 weeks. Any insult to the brain during this period can cause a disorder of neuronal migration. The migrational anomalies have been classified based on which step the cortical development was likely first disturbed. Gray matter heterotopias are supposed to be due to abnormal arrest of radial migration of neurons ${ }^{4}$.

Abnormal or prominent venous drainage has been described in association with cortical dysplasia ${ }^{2}$. The plausible explanation for this is that an abnormal venous drainage from the growing cortex may result in cortical rearrangements that eventually arrest hemispheric development ${ }^{2}$. 


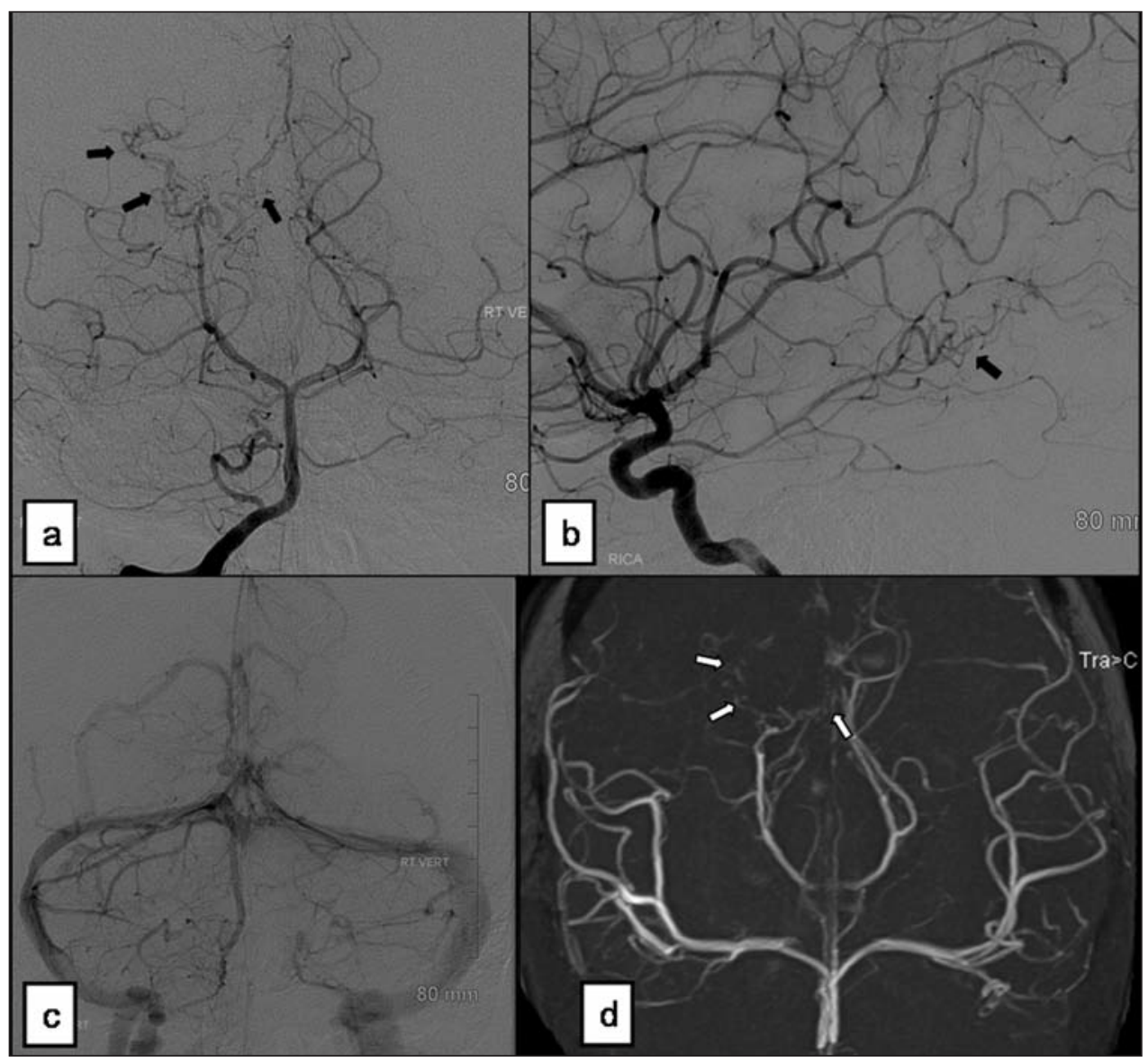

Figure 2: Cerebral angiography. a) AP projection of right vertebral artery injection showing the arterial dysplasia involving the distal branches of the right posterior cerebral artery. (b) Lateral projection of right internal carotid artery injection showing the arterial dysplasia. There is absence of an early draining vein. (c) Normal venous phase of right ICA. (d) The arterial dysplasia depicted on TOF-MRA.

Arterial anomalies along with prominent draining veins have also been described ${ }^{3}$. Abe et al described a case of cortical dysplasia associated with a dilated and ectatic arterial vascular network $^{3}$. There was no early venous drainage in their case; however a large superficial vein was present, draining from the region of the dysplastic cortex. These anomalies did not appear to be arteriovenous shunts or fistulas and the authors suggested the possibility of a vascular reaction to prenatal infection or direct damage to the arterial media resulting in the dysplasia. Our patient is unique in the sense of presenting only arterial dysplasia with no associated venous anomaly.

Two cases of ectatic cerebral arteries with congenital disorders of cellular migration have been reported ${ }^{5,6}$. Doran et al described a suspected case of neuronal migrational anomaly along with dolicoectasia of the anterior cerebral arteries in an adolescent. They have suggested congenital or acquired factor for the histological changes in the vessel wall .

One case of parietal lipoma associated with cortical dysplasia and abnormal vasculature has been reported by Saatci et $\mathrm{al}^{7}$. They showed abnormal arterial vasculature, as well as venous abnormality accompanying the lipoma and the surrounding cortical dysplasia by MR angiography. These lesions are congenital malformations resulting from abnormal persistence and maldifferentiation of the meninx primitiva during the development of the subarachnoid cisterns.

Although most of the cortical dysphasias have been reported with accompanying venous anomaly, we believe that the same possible explanation could be applicable for arterial anomalies as well. The insults for arterial and/or venous anomalies occur in the same embryonic period (4-5 weeks) $)^{2}$, and the neuronal migration starts at approximately the second month of gestation. Similar to the generation of metameric syndromes, if a trigger operating in the embryonic period is selective enough it will either affect only arteries or veins. If the insult is less selective it will give slightly overlapping phenotype and may involve both, arteries and veins. An abnormal arterial supply to or an abnormal venous drainage from the growing cortex may result in cortical rearrangements that eventually give rise to various neuronal migration anomalies.

Various vascular, infectious and teratogenic insults have been suspected in cases of cortical dysplasia. Cytomegalovirus infection has been associated with neuronal migrational disorders ${ }^{4}$. In an autopsy report, tortuous leptomeningeal vessels were noted along with an appearance suggestive of glial 
heterotopia in a 28-week-old fetus with disseminated CMV infection $^{8}$. This suggests that leptomeningeal damage in the embryonic period of neuronal migration could result in dysplastic changes in the arteries along with abnormal arrest of radial migration of neurons.

It is well known that such migration disorders can be associated with Filamin 1 gene mutation and a possible role of the translated protein in cell migration and blood vessel development have been proposed. The phenotype in these cases enjoys wide variability in females and vascular abnormalities are well documented on pathology ${ }^{9}$. We did not have genetic workup done for our patient.

In our case vascular injury secondary to a prenatal insult is a possibility. The other rare possibility of a spontaneously thrombosed arteriovenous malformation can be considered. But there are no signs of arteriovenous shunt in the angiography of our case.

\section{REFERENCES}

1. Barkovich AJ. Abnormal vascular drainage in anomalies of neuronal migration. AJNR Am J Neuroradiol. 1988; 9:939-42.

2. Lasjaunias $P$, terBrugge $K G$, Berenstein A. Venous anomalies and malformations. In: Surgical Neuro-angiography. Volume 3, 2nd ed. Verlag Berlin Heidelberg: Springer; 2006. p. 455-507.

3. Abe T, Singer RJ, Marks MP, Kojima K, Wantanabe M, Uchida M, et al. Arterial vascular abnormality accompanying cerebral cortical dysplasia. AJNR Am J Neuroradiol. 1997; 18: 144-6.

4. Barkovich AJ. Congenital malformations of the brain and skull. In: Pediatric neuroimaging. 2nd ed. New York: Raven Press; 1995. p. 177-275.

5. Doran SE, Deveikis JP, Chandler WF. Dolichoectasia of the anterior cerebral arteries in an adolescent. Am J Neuroradiol. 1995; 16: 1548-50.
6. Araki Y, Mori S, Kanoh M, Maeda Y, Kawai R, Mitomo M. Congenital hemicerebral arterial ectasia complicating unilateral megalencephaly. Br J Radiol. 1987; 60: 359-400.

7. Saatci I, Aslan C, Renda Y, Besim A. Parietal lipoma associated with cortical dysplasia and abnormal vasculature: case report and review of the literature. Am J Neuroradiol. 2000; 21 (9): 1718-21.

8. Norman MG, McGillivray BC, Kalousek DK, Hill A, Poskitt KJ. Congenital malformations of the brain. New York: Oxford University Press; 1995 . p. 257-8.

9. Kakita A, Hayashi S, Moro F, Guerrini R, Ozawa T, Ono K, et al. Bilateral periventricular nodular heterotopia due to filamin 1 gene mutation: widespread glomeruloid microvascular anomaly and dysplastic cytoarchitecture in the cerebral cortex. Acta Neuropathol. 2002; 104(6):649-57. Epub 2002 Jul 23. 